\title{
Understanding Intention to Treat Analysis and Per Protocol Analysis
}

\author{
Vikas Roshan* and Sadamoto Zenda \\ ${ }^{1}$ Department of Radiation Oncology, Shri Mata Vaishno Devi Narayana Superspeciality Hospital, India \\ ${ }^{2}$ Department of Radiation Oncology, National Cancer Center Hospital East, Japan
}

Submission: May 23, 2018; Published: June 25, 2018

*Corresponding author: Dr. Vikas Roshan, Consultant Radiation Oncology, Department of Radiation Oncology, Shri Mata Vaishno Devi Narayana Superspeciality Hospital, Kakryal, Katra, Jammu and Kashmir, 182320, India, Email: roshanvikas@yahoo.com

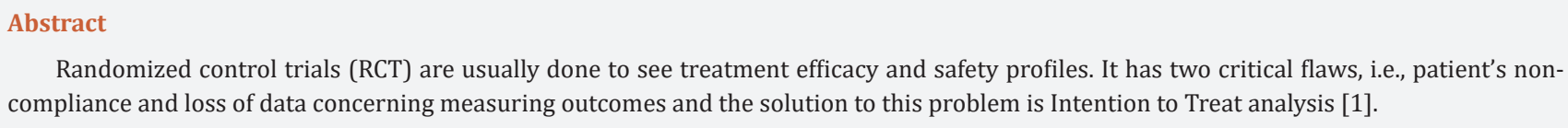

Randomized control trials (RCT) are usually done to see treatment efficacy and safety profiles. It has two critical flaws, i.e., patient's noncompliance and loss of data concerning measuring outcomes and the solution to this problem is Intention to Treat analysis [1].

\section{Introduction}

While conducting clinical trials we come to know about the complexities of analyzing results. There is a lot of protocol violations seen, and as a result, we require some statistical principles to evaluate data and then comes the role of intention to treat analysis (ITT). In randomized controlled trials, ITT use is highly recommended [1-3].

\section{Understanding ITT}

It includes all the patients who are randomized in statistical analysis and usually these patients should be analyzed as per their allocated treatment group even if the patient has refused or discontinued their intervention.

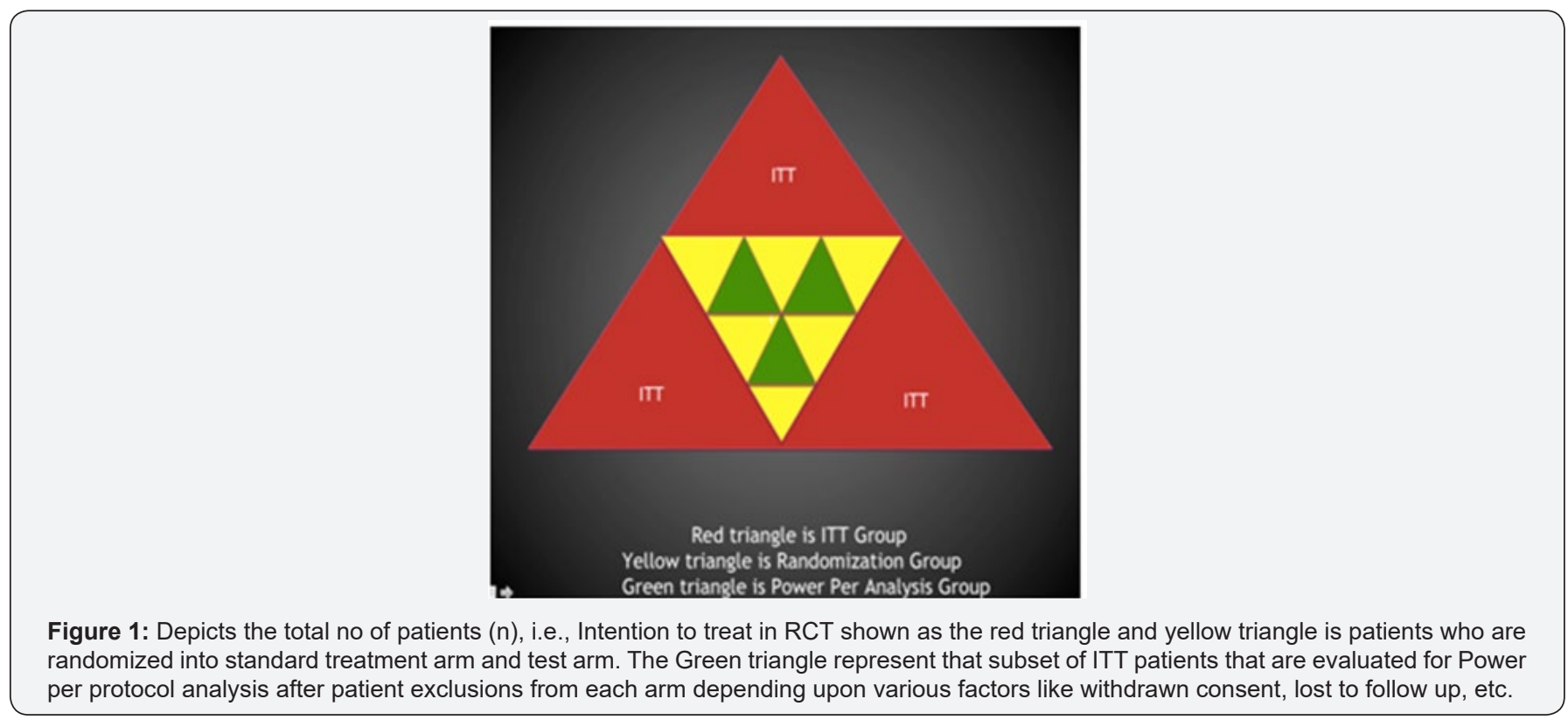

In head and neck cancer study author compared three weekly concurrent chemo radiation versus weekly concurrent Cisplatin. In this study total, 300 patients are randomized into arms of 150 each, but patients who completed treatment are 133 in three weekly arms and 141 in the weekly, but patients included in this trial for ITT are 150 in each division [3-5] (Figure 1). 


\section{Rationale of ITT}

There is significant confusion in the understanding rationale that why we are including the patients in the analysis even if these patients have not received treatment regimen.

These patients are included in the analysis to maintain the rules of randomization because if self-selection excludes patients, then the benefits of randomization are lost as randomization is done to balance the factors in each arm that can introduce bias later on.

The second point of discussion is if we exclude non-adherent patients like in head and neck cancer study, 34 patients excluded from weekly Cisplatin and 18 from three weekly Cisplatin. This point will introduce the bias, and it can be concluded that patients who receive treatment have better outcome ignoring whether treatment is useful or not.

ITT has widespread use in clinical practice as it simulates the real clinical environment because in actual practice also patient doesn't often stick to the treatment depending on the various reasons.

ITT seems very attractive approach to deal with analysis, but there are also few issues associated with it. Suppose if inclusion criteria are not framed strictly and consequently at time of review there is a problem of excluding lot of patients and which in turn leads to violation of randomization.

The problem that we face with ITT is that it overestimates the effect of acceptance of non-compliance, dropping patients who do not adhere to treatment and protocol deviations. Patients who completed treatment as usual responded well and show the substantial effect of treatment. ITT is today standard for analysis in the clinical trial.

ITT preserves the sample size and hence protect the statistical power. It also minimizes type I error, and it is possible to generalize the results of RCT to the general population $[5,6]$.

In contrary to above discussion Per Protocol analysis strictly adhered to the patients who stick to the treatment, so only those patients are analyzed who completed treatment. It gives the reliable estimation of effect between treatment and result. PPA is complicated to apply in clinical practice, and as per evidence, it is weak as compared to ITT. CONSORT (Consolidated Standards of reporting trials) guidelines strongly recommend providing the details of both estimates in clinical trials because when ITT and PPA come to the same conclusion, the confidence level in study results gets increased. There is modified ITT also available that will strictly deal with attrition and allow us to drop patient even after randomization like those patients who never started treatment after randomization. There are limitations to it that it is purely subjective and may allow users to manipulate data. There are no strict guidelines for application [7-10].

\section{References}

1. Fisher LD, Dixon DO, Herson J, Frankowski RK, Hearron MS, et al. (1990) Intention to treat in clinical trials. In: Peace KE (Ed.), Statistical issues in drug research and development. Marcel Dekker, New York, USA, pp. 331-350.

2. Newel DJ (1992) Intention-to-treat analysis: Implications for quantitative and qualitative research. Int J Epidemiol 21(5): 837-841.

3. Wertz RT (1995) Intention to treat: Once randomized, always analyzed. Clin Aphasiol 23: 57-64.

4. Heritier SR, Gebski VJ, Keech AC (2003) Inclusion of patients in clinical trial analysis: The intention-to-treat principle. Med J Aust 179(8): 438440 .

5. Hollis S, Campbell F (1999) What is meant by intention to treat analysis. Survey of published randomized controlled trials. BMJ 319(7211): 670-674.

6. Noronha V, Joshi A, Patil VM, Agarwal J, Ghosh-Laskar S, et al. (2018) Once-a-week versus once-every-3-weeks cisplatin chemoradiation for locally advanced head and neck cancer: a phase III randomized noninferiority trial. J Clin Oncol 36(11): 1064-1072.

7. Moncur RA, Larmer JC (2009) Clinical applicability of Intention-totreat analyses. MUMJ 6: 39-41.

8. Gupta SK (2011) Intention to treat concept: A review. Perspect clin Res 2(3): 109-112.

9. Sainani KL (2010) Making sense of intention-to-treat. PM R 2(3): 209213.

10. D'Agostino RB, Massaro JM, Sullivan LM (2003) Non-inferiority trials: Design concepts and issues -the encounters of academic consultants in statistics. Stat Med 22(2): 169-186.

\section{Your next submission with Juniper Publishers will reach you the below assets}

- Quality Editorial service

- Swift Peer Review

- Reprints availability

- E-prints Service

- Manuscript Podcast for convenient understanding

- Global attainment for your research

- Manuscript accessibility in different formats

( Pdf, E-pub, Full Text, Audio)

- Unceasing customer service

Track the below URL for one-step submission https://juniperpublishers.com/online-submission.php 